EGU2020-6445

https://doi.org/10.5194/egusphere-egu2020-6445

EGU General Assembly 2020

(c) Author(s) 2020. This work is distributed under

the Creative Commons Attribution 4.0 License.

\title{
A new modeling framework for air pollution forecasting in South America
}

Angel Vela, Debora Alvim, Eder Vendrasco, Dirceu Herdies, Nilo Figueroa, and Jayant Penharkar

Biomass burning episodes are quite common in the central region of South America and represent the dominant aerosol sources during the dry/burning, between August and October. Large amounts of trace gases and aerosols injected into the atmosphere from these fire events can then be efficiently transported to urban areas in southeastern South America, thus affecting air quality over those areas. Observational data have been of fundamental importance to understand the evolution and interaction of biomass burning products with meteorology and chemistry. However, supplementing this information with the use of a comprehensive air quality modeling system in order to anticipate very acute air pollution episodes, and thus avoiding severe impacts on human health, is also required. Considering this, a new regional air pollution modeling framework for South America is being implemented by the Center for Weather Forecasting and Climate Studies (CPTEC), the National Weather Service of Brazil. This new system, based on the Weather Research and Forecasting with Chemistry model (WRF-Chem; Grell et al., 2005), is being run experimentally and its operational implementation is underway. The forecasts were driven by global forecast data from the GFS-FV3 model for meteorology and from the WACCM model for chemistry, both data sets provided every 6 hours. WACCM forecasts are employed to map gas and aerosol background concentrations to the WRF-Chem initial and boundary conditions, according to the MOZCART chemical mechanism. Two experiments of 48-hour real-time forecast simulations were performed, on a daily basis, during August and September of 2018 and 2019. The experiment for 2019 includes the very strong 3-week forest fire event when the Metropolitan Area of São Paulo, the largest metropolitan area in South America, plunged into darkness on August 19, with day turning into night. Model results are in good domain-wide agreement with satellite data and also with in situ measurements. Besides forecasts of meteorological parameters, this new system provides forecasts of regional distributions of primary chemical species (CO, SO2, NOx, particulate matter including black carbon), of secondary species (ozone, secondary organic aerosols) and air pollution related health indices, all parameters with a resolution of $20 \mathrm{~km}$ and for the next 72 hours. 